\title{
IMAGENS À DERIVA: \\ INTERLOCUÇÕES ENTRE A ARTE, A PSICANÁLISE E A ANÁLISE DO DISCURSO $^{1}$
}

\author{
Luciene Jung De Campos²
}

Nesta pesquisa procuro observar a descontinuidade da imagem veiculada pela mídia de massa que é apropriada e trabalhada pelo artista. A imagem apresentada pela publicidade/propaganda é tomada como a forma voluntariosa que ao se impor, impulsiona o desejo de construir algo de algo que vem de algo para algo que vai ${ }^{3}$.

A imagem que interessa é a imagem fragmentada e deslocada, que não se ocupa do todo, mas da parte, do detalhe - do resto - que assim adquire potência para veicular o desejo. Esse fragmento assume uma estrutura singular, pois é um recorte no espaço, limitado por contornos que produz suas próprias aparas, indicando o que a imagem não é. E ali onde a imagem é, ocorre a inscrição de um sujeito na função-artista, na história.

O que se coloca não é "o que é visto", mas "como é visto", distanciando-se da idéia positivista que tenta fixar um significado. Esta pesquisa considera que a imagem - enquanto linguagem - não é transparente. Desse modo, ela não busca sentidos secretos, mas indícios que estão na superfície. Produz um conhecimento partindo da imagem como detentora de uma espessura semântica, que lhe confere materialidade própria e significativa, concebendo-a em sua potencialidade discursiva. A construção deste olhar se dá na interface entre os campos da arte, da psicanálise e da análise do discurso, fazendo torções de um campo a outro.

As obras de arte em análise são recortes das séries Perto demais, Outdoor`s e (Re)tratos, dos artistas Daniel Escobar, Carlos Goldgrub e Bianca Araújo, respectivamente. Os três artistas retiram insumos das imagens de outdoors e de jornais para produzir seu trabalho.

A série Perto demais, de Daniel Escobar é uma criação a partir de fragmentos de outdoors, recolhidos pelo próprio artista, que são perfurados e colados em superposição, produzindo uma renda que permite a passagem do olhar do observador pelas múltiplas camadas. Ao reverso, faz a imagem retornar ao seu estado pontilhado inicial. Provoca um furo na mídia massiva, o que só se torna possível a partir de seus próprios resíduos.

Na série Outdoor's, de Carlos Goldgrub, o artista re-fotografa o outdoor e, neste enquadre fotográfico, "limpa" as imagens veiculadas nos prédios e nas ruas da cidade de São Paulo. Geralmente, descarta a imagem dos produtos que estão sendo comercializados e omite o texto que acompanha essas imagens. Privilegia as figuras humanas que estão sendo usadas como modelos para a divulgação dessas mercadorias. Toma seus rostos e corpos, guarda os detalhes e os expõe ampliados nos espaços reservados aos outdoors.

Em (Re)tratos, de Bianca Araújo, a artista apanha fotos de colunas sociais dos jornais, fotocopia e pinta sobre as cópias, num efeito de borrão sobre a imagem. Busca evidenciar os gestos estereotipados dos colunáveis, tais como sorrisos, abanos e abraços. Superpõe a esta imagem, outras notícias e outras imagens que estabelecem relações contraditórias entre si.

Nas três séries, é a cultura popular que oferece matéria-prima a esses artistas. A cultura pop é a herdeira da Revolução Industrial e das revoluções tecnológicas que se seguiram no encontro entre a máquina, a democracia, a moda e o consumo. A cultura pop envolve uma mudança nas atitudes para com os objetos, esses objetos deixam de ser únicos. As coisas que consumimos passam a ser feitas aos milhares e idênticas, sendo impossível distingui-las umas das outras. De fato, o contexto necessário para o surgimento da arte pop é o modo de vida $p o p$, ou melhor, a arte pop é em si um derivado desse estilo de vida. Segundo Stangos (2000, p.165), só nesse sentido e em nenhum outro se pode usar a palavra "estilo" a respeito da arte pop, pois ela é carente de estilo. Salienta que a principal atividade do artista pop, sua justificativa, consiste menos em produzir obras de arte do que em encontrar um sentido, um nexo para o meio à sua

\footnotetext{
${ }^{1}$ Fragmento da tese de doutoramento em Teorias da Linguagem, PPGLET/UFRGS, orientada pela prof. Dra.Maria Cristina Leandro Ferreira, em setembro de 2010.

${ }^{2}$ Psicóloga, doutora em Teorias da Linguagem, Teorias do Texto e do Discurso, PPGLET/UFRGS.

${ }^{3}$ Clarice Lispector. Forma e conteúdo. In: A descoberta do mundo. Rio de Janeiro: Zahar, p. 271.

Organon, Porto Alegre, n $^{\circ} 49$, julho-dezembro, 2010, p.287 - 303
} 
volta, conhecer a lógica daquilo que o cerca em tudo que ele próprio faz. A descoberta dessa lógica, sua forma e direção tornam-se a principal tarefa do artista.

Nesta abordagem, a imagem é tomada como um texto. O texto é a unidade do discurso, especificidade de linguagem como mediação necessária entre o homem e a realidade social. Um meio que o sujeito encontra de significar e significar-se, o trabalho simbólico do discurso está na base da produção da existência humana. Orlandi $(1999$, p.15) afirma que o discurso é essa mediação, que torna possível tanto a permanência e a continuidade quanto o deslocamento e a transformação do homem e da realidade em que vive.

Duchamp, ao comentar sobre o que é uma obra de arte, diz que é algo que "o artista começa e o espectador termina", segundo o que documentou Calvin Tomkins, seu biógrafo (Tomkins, 2005, p.437). Esse ponto de vista se aproxima da noção de discurso de Pêcheux, em que a obra pode ser pensada como um efeito de sentidos entre interlocutores. Levando em conta o homem na sua história, consideram-se os processos e as condições de produção da linguagem responsáveis pelo estabelecimento das relações de força no interior do discurso para estabelecer o sentido. As condições de produção fazem parte da exterioridade lingüística e se relacionam ao contexto sócio-histórico-ideológico na sua extensão mais abrangente. Nessa imbricação, busco uma reflexão sobre a maneira como a linguagem está materializada na ideologia e como a ideologia se manifesta na linguagem. Portanto, a materialidade específica da ideologia é o discurso e a materialidade do discurso é a linguagem na relação imagem-discurso-ideologia.

Pensar com imagens, analisar com imagens, discutir com imagens. Opor, contrapor, articular e relacionar imagens nas transformações estéticas da linguagem comercial para a linguagem poética, nessas intervenções subversivas que trazem para o centro o que está na borda e para dentro o que está fora. Sempre me fascinaram as formas de resistência do sujeito em seu gesto singular de existência, frente ao que está posto como óbvio e evidente. Busco o trabalho de artistas que se apropriam de imagens veiculadas na mídia para apresentar facetas laterais da sociedade em que vivemos.

A imagem original é a publicidade/propaganda, ponto de partida destas obras. Porém, a imagem da publicidade/propaganda está sempre ausente nesta pesquisa, o que interessa são apenas os seus vestígios e resíduos, presentes na produção dos artistas. A materialidade deste objeto de pesquisa é a imagem, mais especificamente, a fotografia e a pintura sobre fotografia que são veiculadas em jornais, outdoors ou revistas de grande circulação. Busco apresentar a descontinuidade entre dois campos: o da publicidade/propaganda (PP) e o das artes visuais (AV), enquanto dois campos de luta, onde um campo se origina da resistência frente ao outro. Esses campos se delimitam e se instalam através dos processos de produção-reproduçãotransformação que são acionados para interpelar o sujeito. Procuro situar as contradições e as alianças inerentes a esses dois procedimentos de interpelação da PP e da AV. A noção de descontinuidade, entre os dois campos (AV e PP), é tratada neste estudo, conforme a perspectiva de Pêcheux (1975) em Semântica e Discurso, enquanto um processo sem fim de retificações coordenadas, que se amparam na emergência de uma posição a ser assumida e fortalecida na adversidade das idéias, como uma luta de classes no campo dos saberes. Desse modo, face à publicidade/propaganda, a arte visual constitui outra produção de conhecimento, cujo funcionamento da imagem é co-extensivo aos efeitos de paráfrase-reformulação no interdiscurso. A arte retira da propaganda aquilo que lhe interessa: um resto, a parte de um todo que sobrou ou que caiu da "imagem total" que a propaganda pretendia oferecer. Porém, a arte enquanto uma prática social funciona como toda prática, isto é, também é uma prática ideológica que interpela. Trata-se de uma descontinuidade de sentido da imagem que, por sua vez, convoca outras posições-sujeito para além da forma-sujeito consumidor.

O que interessa aos meus propósitos é conhecer o processo em que o sujeito na funçãoartista retoma a imagem veiculada pela PP e chega à formação de uma nova apresentação imagética, que aparece intencionalmente/explicitamente vinculada com a primeira, de mídia de massa. É esse vínculo entre as duas (re)-(a)presentações de imagens, em causa, que eu gostaria de restabelecer na discursividade, na medida em que ambas enunciam formações discursivas diferentes, porém uma remete à outra em relações de transformação. 
A linguagem com que estou trabalhando é a imagem veiculada pela publicidade/propaganda ${ }^{4}$ e transformada pela arte visual. Nesta abordagem, a imagem é o elemento estrutural das condições de produção do discurso em questão, cuja materialidade discursiva é a fotografia ou a pintura sobre fotografia, portanto uma estrutura discursivo-visual, como aponta Souza (1998), que exige outros recursos para descrição e análise de sua tessitura. Esta materialidade não pressupõe uma tradução direta ao verbal e nem a simples compreensão do não-verbal perpassado pela linguagem verbal, pois a imagem é uma linguagem com outros modos de significação.

A imagem permite um trajeto do olhar sem roteiro prévio, imprevisível e, assim, torna ativas outras camadas de materialidade do que não está evidente, produzindo uma experiência rara. $\mathrm{O}$ olhar se fixa, contorna e agrupa pontos, construindo delineamentos numa cartografia singular onde se configura o desdobramento do desejo do sujeito. Portanto, o olhar está organizado por algo que não se vê, algo que cai fora do campo da visão e que só adquire sentido na relação com a cultura e com a história. $\quad$ A publicidade/propaganda é a exterioridade da qual o sujeito na função-artista se apropria para realizar a sua obra. Pode ser entendida como o préconstruído, que permite a ele produzir uma nova imagem com formulações distintas e dispersas, articulando-as entre si em formas artísticas determinadas. Ele revisita, apropria-se, opõe, transforma, remete-se à história da arte, aos movimentos artísticos e aos seus representantes. É nesse espaço interdiscursivo - domínio da memória - que se constitui a exterioridade para as apropriações do artista na proposição dos elementos de ressignificação e reapresentação da imagem.

A publicidade/propaganda e a arte visual são duas práticas discursivas. Segundo Michel Pêcheux (1997b, p.213), toda prática discursiva está inscrita no complexo contraditóriodesigual-sobredeterminado das formações discursivas. Essas formações discursivas mantém entre si relações diferenciadas e nelas ocorre um trabalho de reconfiguração.

Nesta pesquisa, a investigação da imagem enquanto uma estrutura discursivo-visual-emfuncionamento se dá através do dispositivo teórico-analítico da Análise do Discurso francesa, fundada por Michel Pêcheux, na interface com a Psicanálise e a Arte. O que interessa neste estudo é indagar: Como funciona esta imagem apropriada? Que estruturas estão organizando esta imagem? Que posições-sujeito estão em jogo? Quais os sentidos que estão em deslizamentos?

Nesta resenha, opto por apresentar duas obras da Série (Re)tratos - da artista gaúcha Bianca Araújo - que são imagens de imagens fotográficas apropriadas de colunas sociais de jornais que colocam em jogo o conceito do retrato no sentido de mostrar-se para um círculo social, ao mesmo tempo que a palavra re-tratar significa tratar de outra forma ou ainda retratação como forma de justificar-se aos outros (Araújo, 2005).

A artista fotocopia a imagem e depois procede à pintura a óleo sobre as imagens. Através das intervenções pictóricas procura ressaltar as poses repetidas, ao interferir nos olhos ou na boca criando os aspectos borrados e desfocados da fotografia original, no intuito de ressaltar gestos que são produtos de aceitação social. A artista acerca-se da pose forjada no enquadramento dos sorrisos padronizados expressos para produzir inscrição em determinada classe social. Massificados, os gestos não guardam singularidade, a não ser pela manipulação que lhes retoca as expressões.

A imagem fotográfica que fora apropriada de um veículo de comunicação de massa transformou-se em fotocópia, depois em pintura e é novamente fotografada pela artista. Essas imagens em positivo revelam uma fusão entre pintura e fotografia, sendo que o jornal também está presente, pois a imagem revela o texto do verso da página, mesmo com a pintura, conserva certa transparência. Neste processo, para descontinuar a imagem veiculada pela mídia de massa,

\footnotetext{
${ }^{4}$ A publicidade é tomada neste estudo como uma atividade profissional dedicada à difusão pública de idéias associadas a empresas, produtos ou serviços, especificamente, propaganda comercial. Comunicação de caráter persuasivo que visa defender os interesses econômicos de uma indústria ou empresa. Já a propaganda tem um significado mais amplo, pois refere-se à qualquer tipo de comunicação tendenciosa, abrangendo as campanhas eleitorais, por exemplo, que busca promover a imagem de pessoas. Portanto, as fotografias em colunas sociais, enquadram-se como propaganda pessoal.
} 
a autora faz retorno ao interdiscurso e reformula a imagem, intervindo através da pintura que é uma técnica medieval, comparada ao recurso contemporâneo da fotografia.

Na obra Casal simpático, a reportagem que está no verso da imagem em texto fragmentado pela ação da pintura e pelo recorte da foto permite ler parte de frases e parte de palavras, tais como: "dônia", "federais e líderes", "está fundamen", "extração ilegal de", "ão une caciqu e gar", "índio", "brancos", "ipal veio d'água". Portanto, a reportagem que está no verso da coluna social, trata de uma provável "ação ilegal relacionada à exploração de recursos naturais que envolve cacique, garimpeiros, brancos e índios em Rondônia".

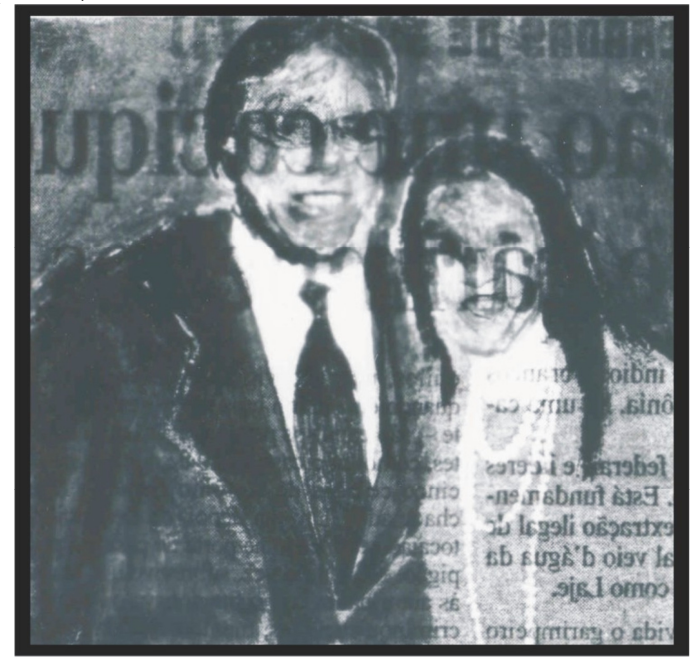

Casal Simpático , 2005, fotografia, 49 × $49 \mathrm{~cm}$

Fig. 1 - Bianca Araújo. Fotograma positivo. Série (Re)tratos, 2005.

Esta imagem funciona como um texto de grande heterogeneidade, atravessado por diferentes formações discursivas. Observa-se um discurso jurídico que regulamenta a exploração e uso de recursos naturais. No entanto, a notícia deixa entrever diferentes sentidos em relação à questão da extração e propriedade desses recursos. Esses sentidos são ressignificados nas diferentes FDs na forma-sujeito garimpeiro e na forma-sujeito índio e na posição-sujeito de cacique e de outras lideranças que não reconhecem o sentido instituído proveniente do discurso jurídico. O texto marca uma polarização entre o discurso jurídico versus o discurso das formas-sujeito de índio e garimpeiro. A forma-sujeito índio e a forma-sujeito garimpeiro são duas posições de sujeito bem marcadas, atravessadas pela idéia de unicidade e de oposição entre elas. No entanto, no momento em que essas duas formas-sujeito se unem numa ação conjunta de interesse comum, deixam em evidência a sua heterogeneidade. Revelam a troca de saberes entre as respectivas formações discursivas que em outros momentos estiveram em oposição, mas que hoje estabelecem alianças.

Portanto, não se trata mais de uma forma-sujeito homogênea; estamos diante de um conjunto de diferentes posições de sujeito, e não apenas duas, e esse rol de posições-sujeito é que vai produzir a forma-sujeito. Por outro lado, uma forma-sujeito fragmentada, como afirma Indursky (2008, p. 18) abre espaço não só para o semelhante, mas também para o diferente, o divergente, o estranho, o que resulta numa formação discursiva heterogênea cuja peculiaridade é a contradição, que a constitui.

Através desta estrutura-discursivo-visual, provoca tensão e estranhamento superpondo à coluna social outra notícia sobre personagens excluídos da história oficial. Aqueles que sofrem um apagamento social e que, facilmente, são conduzidos à ilegalidade. É um exemplo da interpelação ideológica funcionando contra si mesma, conforme refere Pêcheux. E essa é a potência da arte e o compromisso ético das imagens.

A arte e a publicidade produzem uma intervenção com elementos do cotidiano, tornam-se uma força material, que toca os olhos e o coração e aportam possibilidades dialéticas, fazendo com que as evidências do cotidiano não sejam óbvias, mas à deriva. Os traços inconscientes do 
significante não descansam e o sentido é produzido no non-sens pelo deslizamento sem origem do significante. Pêcheux (1975) acrescenta que esse deslizamento [do significante] não desaparece sem deixar traços no sujeito-ego da "forma-sujeito" ideológica, identificada com a evidência de um sentido (Pêcheux, 1997b, p.300).

A descontinuidade de uma superfície - da imagem - para a Arte trata-se de uma reinvenção, de uma exposição, de uma "aventura". Para a Psicanálise, a busca do sujeito em reconhecer um significante capaz de representá-lo. Para a Análise do Discurso, outro discurso, ponto de ruptura que instaura nova rede de dizeres, novas práticas discursivas.

A imagem é uma linguagem que não diz tudo, enquanto saber incompleto, e por isso se deixou apropriar pela arte visual (AV). O fato da publicidade/propaganda (PP) não dizer tudo, é o que faz com que os artistas tenham a dizer, ainda. Toda imagem traz consigo, além do evidente, aquilo que não pode ser simbolizado e integrado. Longe da obsessão de alcançar o todo, pois no todo nada se diz, o artista consegue ver a imagem nesse espaço de falha inerente e abrir novas possibilidades.

A publicidade/propaganda, sob a perspectiva de Althusser (2007), em Aparelhos Ideológicos de Estado, pode ser pensada como um ritual de interpelação ideológica do sistema dominante, uma prática de manutenção e reprodução do capitalismo. Ao passo que a arte, ao se apropriar das imagens veiculadas pela propaganda, procura jogar com o non-sens, urde o equívoco e contamina a ideologia dominante.

Penso que a arte visual e mais diretamente a arte pop no que concerne às estratégias utilizadas na elaboração da imagem, com preponderância da idéia e transitoriedade dos meios, opera um deslocamento com a apropriação de fotogramas de jornais e cartazes veiculados de intensa circulação pública. Essas obras situam-se na mesma seqüencia da série analítica do sonho-lapso-ato falho-witz, apontada por Pêcheux (1975), enquanto falhas no ritual ideológico:

O lapso e o ato falho (falhas do ritual, bloqueio da ordem ideológica) bem que poderiam ter alguma coisa de muito preciso a ver com esse ponto sempre-já aí, essa origem não-detectável da resistência e da revolta: formas de aparição fugidias de alguma coisa "de uma outra ordem", vitórias ínfimas que, no tempo de um relâmpago, colocam em xeque a ideologia dominante tirando partido do seu desequilíbrio" (Pêcheux, 1997b, p. 301, o grifo é meu).

Nessa constatação de Pêcheux, posso observar o seu interesse nas produções do inconsciente, todavia com um foco diferente daquele de Freud, pois a Pêcheux mais do que a vinculação aos processos mentais, interessa e desafia a ligação existente dessas erupções com a ideologia, no intuito de analisar como essas presenças fazem furo nas práticas sociais. Assim, a série analítica subversiva sonho-lapso-ato falho-witz é tomada como uma outra forma de presença, até então ausente.

Quanto às Séries artísticas Outdoor`s, (Re)tratos e Perto demais em análise no presente estudo, também as vejo como "séries subversivas", imprevisíveis, que se revoltam e desequilibram as evidências da sociedade de consumo, enquanto falha do ritual e bloqueio da ordem ideológica no seio do aparelho de reprodução da publicidade e propaganda. Por isso, parece-me possível estabelecer um diálogo direto entre os dois pensadores, Freud e Pêcheux, para pensar a presença intangível dos processos de deslocamento e condensação que vão determinar o jogo entre aquilo que deve e não deve ficar ausente para que o evidente se desinstale.

Pêcheux (1997b) assinala uma característica atemporal (sempre-já aí) e intangível de um detonador que provoca fissuras na ideologia dominante. Essa questão da atemporalidade é apresentada por Freud (1976a) em A interpretação de sonhos (1900), como uma das características do inconsciente. Na Psicopatologia da vida cotidiana (1901), além dessas constatações sobre as manifestações do inconsciente no consciente, ele aborda as manifestações do inconsciente como visíveis na trivialidade do dia-a-dia. Portanto, não estão soterradas nas profundezas da mente, mas justamente, elas aparecem enquanto uma aparição fugidia, como assinala Pêcheux. Pode-se observar que os dois autores compreendem os fenômenos inconscientes numa dimensão moebiana, de dupla face, que relampeja sob leve torção da superfície. 
Para Freud (1905), o chiste (witz) é a capacidade de deslocamento de energia psíquica ao longo de certos trajetos associativos que sugere uma tentativa de figurar de outra forma o desconhecido. Esse processo "submete" alguns elementos, dos quais retira a energia, em prol de outros elementos que receberão esta energia desinvestida, agora reinvestida. Certamente, essa energia psíquica que se desloca, a que se refere Freud, vem acompanhada de uma idéia inconsciente que irrompe na consciência. Ou seja, algo que estava ausente, precisou fazer um percurso entre um sistema e outro para se fazer presente, havendo uma alteração da cartografia da consciência.

Neste sentido, também se podem relacionar as formações discursivas que se comunicam no interdiscurso, enquanto fronteiras deformáveis que se afetam mutuamente. Penso que existe um funcionamento análogo na forma-sujeito, por exemplo, em que alguns elementos constitutivos da formação discursiva (FD) são desinvestidos e ficam submetidos a outros que recebem um reinvestimento, fazendo deslocar a idéia e migrar o sentido de um espaço para outro.

Portanto, construir e compartilhar uma série analítica subversiva ou uma série artística pressupõe interpelação ideológica que possibilite a transcrição mutilada e alterada de certas estruturas e que ainda assim elas possam ser reconhecidas. Esses processos, que são da ordem do intangível, pressupõem deslocamento e condensação. É preciso que o autor do chiste e seu ouvinte, ou o artista e o observador, transitem em formações discursivas com relativa proximidade, em função da heterogeneidade e permeabilidade das FDs, o que vai permitir ao artista e, ao observador de sua obra, novas tomadas de posição.

Procuro observar os processos de condensação e deslocamento e analisar os movimentos metafóricos e metonímicos na imagem - guardiões da supremacia do significante. Com esse intuito, faço retorno a Freud, mais especificamente ao capítulo IV de A Interpretação de Sonhos (1900), onde é abordada a deformação nos sonhos.

Freud diz ainda que a primeira coisa que aparece clara é que o sonho é um roteiro pictórico em que se efetuou um amplo trabalho de condensação: Os sonhos são breves, insuficientes $e$ lacônicos [...](Freud, 1976a, p.297). Salienta ainda que a análise de um sonho, muitas vezes, é maior que a sua descrição e de fato nunca se tem a certeza de que um sonho foi completamente interpretado. Assinala ser comum termos a impressão de que sonhamos durante toda a noite, mas ao acordarmos, lembramos apenas de uma pequena cena. Segundo ele, isso implica que o material psíquico passou por extenso processo de condensação no processo de construção do sonho: Sob este ponto de vista, o sonho que recordamos quando acordamos seria apenas um remanescente fragmentário da elaboração do sonho total (Freud, 1976a, p. 297).

No famoso capítulo VI de A interpretação de sonhos (1900), Freud registra o processo de criação de pessoas coletivas ou pessoas que foram sacrificadas ao longo do trabalho de condensação na construção do sonho. Trata-se de um tipo de condensação que se dá através da superposição e fusão do material latente. Nesta linha, busco uma aproximação entre o quadro pictórico nos sonhos e as imagens na presente análise, onde a imagem se apresenta como uma cena condensada. Abaixo, A linda, outra obra da série (Re)tratos que permite problematizar essa questão: 


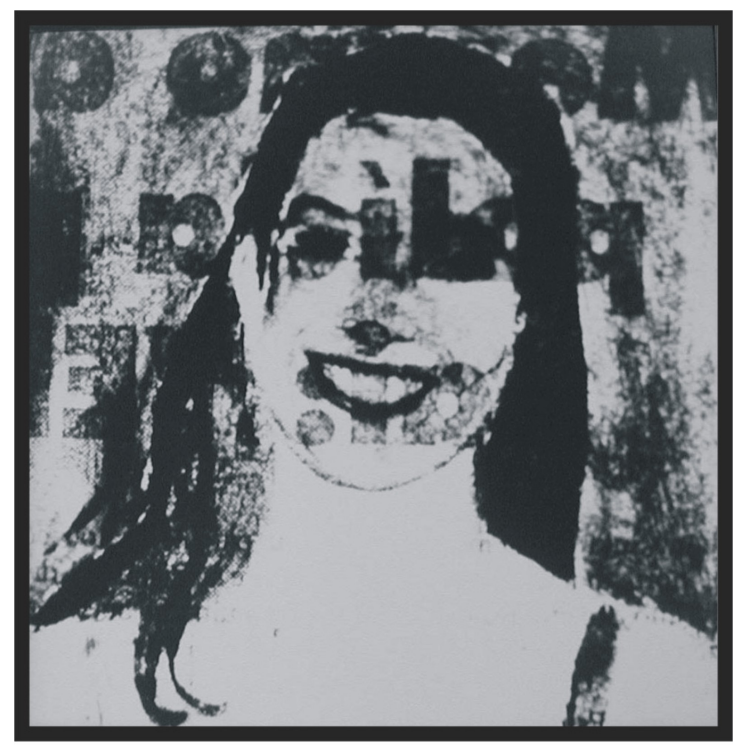

A linda , 2005, fotografia, 44,3 $344,3 \mathrm{~cm}$

Fig. 2 - Bianca Araújo. Série (Re)tratos

Aqui, o personagem colunável é "sacrificado" através da fusão entre a fotografia e a pintura que dissimula os traços originais da foto, que em seguida é superposta à página policial, constituindo uma nova personagem condensada. A página de jornal é a base comum que reúne os personagens em diferentes formações sociais no mesmo momento sócio-histórico. A foto inicial, assim como seu título A linda é de uma pessoa, mas o texto "Menino ... polícia" escrito no verso da página, é o discurso sobre outras pessoas que sofreram apagamento de sua imagem corporal, suprimida na obra, restando somente o relato de sua experiência trágica. Essa imagem compósita força uma estranha identificação entre as duas personagens pela notoriedade, que é o elemento comum em situação. A notoriedade é o componente que justifica a seleção das duas páginas que foram combinadas, que parece como o elemento comum ao mesmo tempo deslocado e combinado. $\mathrm{O}$ processo duplica a personagem e a divide. Permite a emergência do outro, do duplo. Revela a tensão entre o eu e o outro na cultura. Nesta série, a artista não busca o oculto, mas não desconhece o espelho. Faz a travessia de uma superfície e introduz a questão do estranhamente familiar: "O que quer esse outro que fala em mim?"

Ao se questionar sobre os meios que os sonhos possuem para lidar com as diferentes idéias que estão em cena, Freud faz relação direta entre a plástica dos sonhos e a estética das artes visuais. Afirma a imagem como materialidade tanto dos sonhos quanto das artes visuais. Freud admite diferentes formas de apresentação da linguagem que se materializam nos sonhos, nas artes plásticas e na poesia. A construção de figuras coletivas e compostas é um dos principais métodos pelos quais a condensação atua nos sonhos e talvez na arte, aspecto que interessa discutir. Novas entidades são arquitetadas sob a forma de estruturas compostas e, assim, entidades comuns ou intermediárias são construídas. As agregações aparentemente caóticas associadas a uma imagem anterior possuem um sentido e transmitem novos conhecimentos.

A imagem, quando examinada pelo observatório do discurso, perde a aparência inicial de absurdo e assume o aspecto de um discurso que admite o equívoco. Mostra em seus caracteres visuais, vestígios de aspectos inconciliáveis, numa comunicação contemporânea e preciosa. Para a $\mathrm{AD}$, não é o conteúdo que deve ser privilegiado, pois a imagem não remete à transparência, mas à torção na forma, que tem a potência para colocar no centro, algo que estava na borda.

Lacan retoma o mesmo texto de Freud- A interpretação de sonhos - para sustentar a hipótese do inconsciente estruturado como uma linguagem. Para isso, detém-se no processo de trabalho do sonho, que consiste no funcionamento dos diversos mecanismos inconscientes. Aproxima esses mecanismos de condensação e deslocamento dos dois grandes eixos da 
linguagem: substituição/metáfora e combinação/ metonímia. Na abordagem lacaniana, o processo de condensação do sonho é compreendido como um processo metafórico. Ao passo, que o processo de deslocamento é tido como um mecanismo metonímico.

Lacan reteoriza as idéias de Saussure onde não se trata mais de aceitar a idéia de "corte" que une o significante ao significado na determinação simultânea, mas de introduzir essa delimitação através do conceito de ponto-de-estofo. Esta inovação surge a partir da sua experiência psicanalítica onde pode ser observada a relação fluida entre significante e significado, sempre pronta a se desfazer. O ponto-de-estofo é a operação pela qual o significante detém o deslizamento indeterminado e infinito da significação. É aquilo por meio do qual o significante se associa ao significado na cadeia discursiva. É o significante que governa no discurso do sujeito; ou melhor, é ele que governa o próprio sujeito.

Em Escritos (1966), Lacan (1998b) vai definir a metáfora como a implantação numa cadeia de significantes de um outro significante num perpétuo intervalo onde outra cadeia de significantes possa entrar. Na série (Re)tratos, a artista condensa numa formação compósita a coluna social e a página policial, ou seja, ela faz surgir o sentido através do "sem sentido", do non-sens. A metáfora consiste em substituir o significante para derrubar o significado, o que se pode observar na inserção da página policial no verso da coluna social. O significante novo (página policial) é o significante latente que aparece no perpétuo intervalo onde ele é introduzido na cadeia de significantes anterior (coluna social).

Neste intervalo, a artista se inscreve como autora de uma nova obra, onde a página policial pode estar ligada a outra cadeia de significantes. Propõe um outro sentido, abre para outros discursos. Neste ponto em que a significação se engendra no significante, a artista está implicada na metáfora.

A metáfora condensa em si a posição do sujeito ideológico no interior das formações discursivas. A artista está, ela mesma, implicada na metáfora e convocada a se implicar numa posição. A metáfora não é simplesmente uma obra do acaso ou a distorção de uma imagem, nem a expressão de um sentido óbvio. Mas, é o inconsciente que se oferece como recurso do pensamento e da resistência. O que permite estranhar a imagem publicitária dada.

A artista trabalha na resistência que o material imagético oferece e busca um meio de contornar a sua opacidade. É a presença do sujeito da linguagem que não se expressa com a linguagem, mas através da linguagem. Remete à questão de que o sujeito na emergência de forças opostas é o artesão de seus suportes. Os significantes são modelados pelo sujeito, talvez mais com suas mãos do que com seu intelecto. Conforme refere Lacan (1997), sobre o pote de barro presente em todas as civilizações para sinalizar a presença humana e a presença do significante no jogo do cheio e do vazio.

A intervenção na imagem com pintura se constitui em outro significante no perpétuo intervalo na cadeia de significantes. É a imagem metafórica que resulta num espaço saturado de significantes, onde fotografia, pintura e texto se justapõem. O texto não diz respeito à imagem. Conta outras histórias fragmentadas; incompleto, não pode ser lido na íntegra. Assinala a existência de outras presenças e de outras classes sociais, das quais a coluna social não dá conta, pois reconhece a existência de apenas uma classe.

A coluna social aparece como a imagem oceânica, a imagem para ser vista e para satisfazer, no entanto, essa imagem é uma imagem que frustra. Enquanto imagem simbólica, ela aparece contraditória. Por um lado, reforça a onipotência do leitor através da identificação com a imagem idealizada do colunável; por outro lado, assinala a sua impotência. Impotência não só no sentido de ascensão social, mas também na sua incapacidade para resolver as desigualdades sociais em que está imerso. Nos dois sentidos, a imagem assujeita o observador. No plano ideológico, sempre que houver dominação vai haver resistência, frente a isso o artista recria o seu mundo simbólico, pois é um sujeito de linguagem.

O sujeito na função-artista é interpelado pela imagem da publicidade, no caso, a coluna social. Mergulha no interdiscurso e retira elementos para articular o fio de seu discurso, expresso na sua obra: a Série (Re)tratos, que tomada discursivamente se constitui em uma metáfora condensada que faz a mediação entre a imagem publicitária e o artista, na descontinuidade. No ato de recriação da imagem o artista implanta na cadeia de significantes "coluna social" um outro significante que é a "pintura sobre a fotografia". Assim, quebra o 
significado anterior da cadeia de significantes "coluna social" que perde o sentido. Neste perpétuo intervalo entre um significante e outro, a autora introduz na cadeia de significantes um segundo significante, que é a página policial. Dessa forma ela vai substituindo uma imagem por outra.

A metáfora, como é tomada nesse estudo, condensa em si o movimento do sujeito nas suas tomadas de posição através das imagens. A metáfora se apresenta como a trama do pensamento no inconsciente, onde o sujeito é sujeito do desejo. É o sujeito do desejo que resiste enquanto assujeitado no interior de uma formação discursiva para "livremente" se submeter a outra, dissimulando o seu assujeitamento. A metáfora não é simplesmente uma deturpação do sentido dado de uma imagem. Articuladora do inconsciente ela aparece como uma figura essencial, segundo a qual é o inconsciente que se dá como pensamento, onde isso mo(n)stra.

Penso que seria possível estabelecer alguma relação entre os processos metafóricos e metonímicos com as formações discursivas, pois a ideologia faz a mediação entre o sujeitoartista e a imagem. O significante é o furo da imagem, onde podem ser depositados os sentidos ideológicos, a partir da formação discursiva com que o artista está identificado. É essa matriz de sentido que permite com que o artista apresente o que pode ser mostrado.

No esquema imagético, o que faz com que um fragmento visual se torne concreto, fazendo sentido, são suas relações de oposição que mantém na cadeia imagética. A imagem aparece como uma série de divisões simultaneamente introduzidas num fluxo de pensamentos e num fluxo visual. Assim, o papel da imagem não é criar um meio visual para a expressão de idéias, mas ocupar um lugar intermediário entre o pensamento e o olhar, que conduza necessariamente a delimitações recíprocas de unidades numa formação discursiva.

O devir da imagem, que ao longo de seu percurso é trocada por diversos substitutos, nos remete à ordem da linguagem e a seus mecanismos de substituições significantes. Os personagens da coluna social e da página policial determinados pela sua relação com a mídia nos conduzem à forma-sujeito, movida à revelia pelos significantes da linguagem em relação com o inconsciente e a ideologia. Nas imagens em análise, o que está problematizado é a posição-sujeito, enquanto lugar imaginário, representando no processo discursivo os lugares ocupados pelos sujeitos na estrutura de uma formação social. Deste modo, o mecanismo de condensação na obra nos mostra que não há um sujeito único, mas diversas posições-sujeito, as quais estão relacionadas com determinadas formações discursivas e ideológicas. Deste modo, a supremacia do significante se demonstra por uma dominação do sujeito pelo significante, que o determina desde onde ele pensa escapar: a toda a determinação de uma linguagem que ele imagina controlar.

O sujeito na função-artista se posiciona no corte, ou seja, no intervalo entre um significante e outro. Portanto, as séries marcam o momento inaugural do sujeito, algo do real que se manifesta no simbólico e que o excede sempre, para além do simbólico, fazendo retornar o sujeito da falta. O sujeito na função-artista se inscreve no espaço de contra-identificação, no momento da suspensão de sentido, ligeiro momento de dessubjetivação onde se dá o eclipse da forma-sujeito. O sujeito na função-artista é essa brecha que se abre entre uma posição e outra, entre diferentes formações discursivas.

A descontinuidade da imagem aparece nesse espaço de real no simbólico em que o ponto de existência do sujeito é o ponto de separação e de intercâmbio entre a posição-sujeito e a formação discursiva que o domina na trama simbólica. A descontinuidade é o mais além do simbólico, propriamente, a dimensão do real na que eclode e faz insistir no desejo e resistir na ideologia.

E quanto à interlocução dos três campos no tratamento das imagens, eu arriscaria apontar algumas diferenças quanto à heterogeneidade dos olhares. O olhar da Psicanálise se detém nos fragmentos, acentua a significação dos detalhes, se perde em detalhes mínimos para encontrar melhor o reprimido, o recalcado, o forcluído. O olhar da Arte vai inventar uma prática discursiva na tentativa de transformar o que está posto como destino. A AD desloca o olhar, reconstrói uma história negada, torna exposto e elegível as contradições. Engendra novas leituras que são outros tantos novos olhares, na tentativa de invenção do futuro com uma pluralidade de inquietudes inaugurais. 


\section{BIBLIOGRAFIA}

ALTHUSSER, Louis. Aparelhos ideológicos de estado. 10ed. Rio de Janeiro: Graal, 2007.

ARAUJO, Bianca Silveira De. (Re)tratos que revelam palavras: uma poética entre a pintura e a fotografia. Monografia (Especialização em Poéticas Visuais: Gravura, Fotografia e Imagem Digital) Curso de Pós-Graduação, Instituto de Ciências Humanas, Letras e Artes. Centro Universitário Feevale, 2005. Novo Hamburgo: FEEVALE, 2005.

FREUD, Sigmund. A interpretação de sonhos (1900). In: Obras Completas Edição Standard Brasileira. RJ: Imago, 1976a.

FREUD, Sigmund. A psicopatologia da vida cotidiana (1901). In: Obras Completas Edição Standard Brasileira. RJ: Imago, 1976 b.

FREUD, Sigmund. Os chistes e sua relação com o inconsciente (1905). In: Obras Completas Edição Standard Brasileira. RJ: Imago, 1976c.

FREUD, Sigmund. O Estranho (1919). In: Obras Completas. Edição Standard Brasileira. Rio de Janeiro, Imago, 1976d.

INDURSKY, Freda. Unicidade, desdobramento, fragmentação: a trajetória da noção de sujeito em Análise do Discurso. In: MITTMANN, Solange; GRIGOLETTO, Evandra; CAZARIN, Ercília A. (orgs.) Práticas discursivas e identitárias: sujeito e língua. Porto Alegre: Nova Prova, 2008.

LACAN, Jacques. O seminário, livro 7: a ética na psicanálise (1959-1960); texto estabelecido por Jacques Alain-Miller; tradução de Antônio Quinet. (Campo Freudiano no Brasil). Rio de Janeiro: Jorge Zahar Editor, 1997.

LACAN, Jacques. Escritos (Campo Freudiano no Brasil). Rio de Janeiro: Jorge Zahar Editor, 1998b.

ORLANDI, Eni. Análise do discurso: princípios e procedimentos. Campinas: Pontes, 1999.

PÊCHEUX, Michel. Semântica e discurso: uma crítica à afirmação do óbvio (1975). Tradução Eni Orlandi [et al.] 3.ed. Campinas: Ed. UNICAMP, 1997b.

SOUZA, Tania Clemente de. Uma abordagem discursiva de "Limite". Estudos sobre "Limite" de Mário Peixoto. Rio de Janeiro: Laboratório de Investigação Audiovisual, Universidade Federal Fluminense, 1998 [cd-rom].

STANGOS, Nikos. Conceitos da arte moderna. Rio de Janeiro: Jorge Zahar, 2000.

TOMKINS, Calvin. Duchamp: uma biografia. São Paulo: Cosac Naify, 2004. 